\title{
NURSING CARE FOR POSTPARTUM PREGNANT WOMEN WITH EPISIOTOMY STITCHES AT HAU GIANG OBSTETRICS AND PEDIATRICS HOSPITAL IN 2020-2021
}

\author{
Vo Thi Le Hoang ${ }^{1}$, Pham Nhu Thao ${ }^{1}$, Le Thi Binh ${ }^{2}$ \\ ${ }^{1} \mathrm{Hau}$ Giang Obstetrics and Pediatrics Hospital; ${ }^{2}$ Thang Long University
}

\begin{abstract}
Objective: To describe nursing care for postpartum pregnant women with episiotomy stitches at Hau Giang Obstetrics and Pediatrics Hospital in 2020-2021. Subjects and method: A cross-sectional study was conducted on 385 postpartum women with episiotomy stitches at Hau Giang Obstetrics and Pediatrics Hospital from November 2020 to April 2021. The data was collected by using checklists, interviewing, and getting information from the patient's medical records. Results: Most of patients had the episiotomy stitch classification at grade I (97.9\%). $73.2 \%$ of the subjects had an episiotomy stitch at the 7 o'clock position. $73 \%$ of women had episiotomy (73.0\%), most of the episiotomy was sutured with undissolved sutures. $83.4 \%$ of subjects had severe pain/severe (85.5\%). However, only $26.2 \%$ had postpartum complications (common is urinary retention, postpartum haemorrhage). Outcomes of care: $69.4 \%$ of women have good knowledge of episiotomy stitches care; $98.7 \%$ of women are satisfied with the nurses in monitoring and caring for the episiotomy stitches. Most of the women had a decrease in pain on the 3rd day compared to postpartum (95.8\%). Results of maternal care are good, accounting for $64.2 \%$. Conclusion: Nursing care for postpartum women with episiotomy stitches improved postpartum symptoms.
\end{abstract}

Keywords: postpartum nusing care, episiotomy stitches, Hau Giang Obstetrics and Pediatrics Hospital.

\section{INTRODUCTION}

An episiotomy is a surgical incision made in the area between the vagina and anus. It is used to enlarge the vaginal opening before delivery. After the baby is delivered, stitches are used to close the incision as well as repair any tears. Taking good care of episiotomy stitches during postpartum recovery will minimize the risk of infection and can help manage pain. In Vietnam, episiotomy has become quite common in normal deliveries. According to Nguyen Duc Hinh (2002), rate of episiotomy in the first child birth accounted for $91.7 \%$, for the second child onwards only $66.8 \%$ [1]. The main concern in episiotomy is the possible complications, although there is no statistical association between the occurrence of complications and episiotomy. Because many cases of severe tearing were not reported. This rate ranges from $0-4.5 \%$ and varies from hospital to hospital [2, 3]. According to the World Health Organization,
Cor. author: Vo Thi Le Hoang

Address: Hau Giang Obstetrics and Pediatrics Hospital

Email: vthilehoang@gmail.com
Received: Jan 11, 2022

Accepted: Feb 28, 2022

Published: Mar 01, 2022 
postpartum care includes monitoring and referring the mother to treatment if there are complications such as bleeding, pain, infection. In particular, episiotomy stitches care plays an important role, contributing to reducing the rate of infection of the episiotomy suture and reducing the rate of postpartum infection. Department of Obstetrics and Gynecology, Hau Giang Obstetrics and Pediatrics Hospital, is one of the locations responsible for examining and treating obstetrics and gynecological diseases for people in Hau Giang province and neighboring communes and districts. According to statistics in 2019, the hospital received 3,763 pregnant women to give birth, an increase of $9.96 \%$ compared to 2018 [4]. However, not many studies have been performed regarding the care of episiotomy stitches in pregnant women. Therefore, we conducted a study on "Postpartum care for pregnant women with episiotomy stitches at Hau Giang Obstetrics and Pediatrics Hospital in 2020-2021". The objective of study was describing nursing care for postpartum pregnant women with episiotomy stitches at Hau Giang Obstetrics and Pediatrics Hospital in 2020-2021.

\section{RESEARCH SUBJECTS AND METHODS}

\subsection{Research subjects}

Postpartum pregnant women with episiotomy stitches are hospitalized at $\mathrm{Hau}$ Giang Obstetrics and Pediatrics Hospital.

Inclusion criteria: Women over 18 years old, normal birth with episiotomy stitches.

Exclusion criteria: stillbirth, birth defects. Pregnant women with serious physical and mental illnesses.

\subsection{Research period and setting}

Research period: from November, 2020 to April, 2021

Research setting: Hau Giang Obstetrics and Pediatrics Hospital

2.3. Study design: A prospective descriptive study.

\subsection{Sample size and sampling} method

- Sample size: apply the formula to calculate sample size for proportion estimate:

$$
n=Z_{1-\alpha / 2}^{2} \frac{p(1-p)}{d^{2}}
$$

$\mathrm{n}$ : Sample size required

$\mathrm{p}$ : The percentage of good care for episiotomy stitches evaluated, choose $\mathrm{p}=0.5$

$\Delta:$ Allowable deviation between the rate obtained from the study sample and the rate of the population. Deviation $5 \%, \Delta=0.05$.

$Z \alpha / 2$ : The $Z$ value obtained from the $Z$ table corresponds to the selected $\alpha$ value

$\alpha$ : Significance level with $\alpha=0.05, Z$ coefficient $(1-\alpha / 2)=1.96$

$\rightarrow \mathrm{n}=385$ patients

- Sampling method: Using convenient sampling method

\subsection{Data collection}

Data was collected by using the questionnaires.

Data collection methods: interviews using questionnaires, using checklists and getting information patient's medical records.

Data collection procedures: The investigator made a list of eligible mothers 
to invite to participate in the study. After the mother was transferred to the postpartum room (from 0-3 days after giving birth), the investigator met to introduce the study. If mothers agreed to participate, they were invited to sign a consent form to participate in the study. Investigators conducted interviews and monitored episiotomy stitches using checklists and medical records.

\subsection{Research variables, evaluation criteria}

- Variables:

+ General characteristics of pregnant women: age, occupation, education level, number of births.

+ Clinical characteristics: episiotomy suture characteristics, episiotomy tear, episiotomy site, additional tear, postpartum complications, pain.

+ Results of care: Results of taking care of stitches; Results provide knowledge of episiotomy stitches care; Satisfaction with nursing care; General care outcomes.

+ Pain level: using the VAS Scale 0-10 points to assess the pain level of pregnant women at 2 time points: 2 hours after birth and at hospital discharge time.

- Evaluation criteria:

+ Episiotomy stitches care: assessment at $2 \mathrm{~h}, 3-6 \mathrm{~h}, 7 \mathrm{~h}, 3$ days, 4 days, 5 days after birth:

Stitches (abnormal: infected swelling, heat, redness, pain, oozing, open sutures; normal)

Odor of discharge (abnormal: foulsmelling vaginal discharge; normal)

Color of discharge (abnormal: blood, cloudy discharge; normal)
+ Good episiotomy stitches care: there is no sign of infection of the stitches, no foul smell of vaginal discharge, normal discharge.

+ Episiotomy stitches care knowledge: assessing at hospital discharge time with 24 questions (According to the National Standard Guidelines for Reproductive Health Services [5]):

Good: the mother has knowledge score from 18/ 24;

Not good: the mother has knowledge score below 18/24.

+ Overall care results:

Good: good suture care, reduced pain level, satisfied with nursing care, good knowledge of suture care.

\subsection{Data analysis}

The data were synthesized by using SPSS 20.0 software.

Descriptive statistical including mean, percentage, standard deviation were used to describe variables of study.

\subsection{Research ethics}

The research proposal was approved by the Ethical Review Board of Thang Long University Council the Scientific Council of Hau Giang Obstetrics and Pediatrics Hospital. An informed consent was obtained to ensure that the subjects voluntarily participated in this study. the women participating in the study were provided with full information about the study including the purpose, research methods and rights when participating in the study. Participants have the right to withdraw from the study at any time

The responses would be kept strictly confidential, and their identity will not be revealed, only use for research purposes. 


\section{RESULTS}

The mean age of the study subjects was $26.4( \pm 6.59)$ years old. The majority of pregnant women are under 35 years old $(87.0 \%)$. The majority of pregnant women work as farmers $(39.7 \%) .73 \%$ of pregnant women live in rural areas. The majority of pregnant women have lower secondary education $(41.3 \%)$. Nearly half of women giving birth for the first time $(46.8 \%)$.

\subsection{Clinical characteristics of postpartum pregnant women with episiotomy stitches}

Table 1. Characteristics of episiotomy stitches of pregnant women

\begin{tabular}{|c|c|c|c|}
\hline \multicolumn{2}{|c|}{ Characteristics } & Frequency & $\%$ \\
\hline \multirow{2}{*}{ Episiotomy stitches level } & Level I & 250 & 97.9 \\
\hline & Level II & 8 & 2.1 \\
\hline \multirow{3}{*}{ Position of episiotomy stitches } & 5 o'clock & 1 & 0.3 \\
\hline & 6 o'clock & 102 & 26.5 \\
\hline & 7 o'clock & 282 & 73.2 \\
\hline \multirow{2}{*}{ Episiotomy tear condition } & Episiotomy tear & 104 & 27.0 \\
\hline & Cut episiotomy & 281 & 73.0 \\
\hline \multirow{2}{*}{ Is there more tearing? } & Yes & 131 & 34.0 \\
\hline & No & 254 & 66.0 \\
\hline \multirow{2}{*}{ Type of episiotomy suture } & Absorbable suture & 64 & 16.6 \\
\hline & Nonabsorbable suture & 321 & 83.4 \\
\hline \multirow{7}{*}{ Postpartum pain level } & No pain & 0 & 0.0 \\
\hline & Mild pain & 16 & 4.2 \\
\hline & Moderate pain & 40 & 10.4 \\
\hline & Severe pain & 214 & 55.6 \\
\hline & Very severe pain & 112 & 29.1 \\
\hline & Worst possible pain & 3 & 0.7 \\
\hline & Total & 385 & 100 \\
\hline
\end{tabular}

$97.9 \%$ of pregnant women have episiotomy stitches at level I. Nearly three-quarters of women have episiotomy I stitches at 7 o'clock position (73.2\%). $73.0 \%$ of pregnant women had cut episiotomy, $27.0 \%$ had an episiotomy tear. The rate of women with extra episiotomy tear was $34.0 \%$. $83.4 \%$ of subjects were used nonabsorbable suture. After giving birth, the majority of pregnant women have pain at three level: severe pain, very severe pain, worst possible pain $(75.4 \%)$. 
Table 2. Postpartum complications of pregnant women

\begin{tabular}{|lcc|}
\hline \multicolumn{1}{|c}{ Characteristics } & Frequency & $\%$ \\
\hline Postpartum complications & 101 & 26.2 \\
Yes & 284 & 73.8 \\
No & & \\
\hline Type of postpartum complications (n=101) & 1 & 1.0 \\
Episiotomy tear level III - IV & 24 & 23.7 \\
Postpartum haemorrhage & 3 & 3.0 \\
Infection & 10 & 10.0 \\
Vaginal episiotomy hematoma & 49 & 48.5 \\
urinary retention after birth & 14 & 13.8 \\
Other complications & 101 & 100 \\
\hline Total & & \\
\hline
\end{tabular}

There are $26.2 \%$ of women with postpartum complications. The rate of complications in 101 pregnant women with complications was quite different: urinary retention after childbirth (48.5\%); postpartum hemorrhage (23.7\%); Vaginal episiotomy hematoma (10.0\%); infection (3\%) and episiotomy tear level III - IV was 1.0\%.

\subsection{Results of postpartum care for women with episiotomy stitches}

Table 3. Monitor episiotomy stitches

\begin{tabular}{|c|c|c|c|c|c|c|}
\hline Contents & $\begin{array}{l}2 \text { hours } \\
\text { after birth } \\
(n=385)\end{array}$ & $\begin{array}{l}3 \text { - } 6 \text { hours } \\
\text { after birth } \\
(n=385)\end{array}$ & $\begin{array}{l}7 \text { hours } \\
\text { after birth } \\
(n=385)\end{array}$ & $\begin{array}{c}3 \text { days } \\
\text { after birth } \\
(n=385)\end{array}$ & $\begin{array}{c}4 \text { days } \\
\text { after birth } \\
(n=336)\end{array}$ & $\begin{array}{l}5 \text { days } \\
\text { after birth } \\
(n=223)\end{array}$ \\
\hline \multicolumn{7}{|l|}{ Stitches } \\
\hline Normal & $\begin{array}{c}265 \\
(68.8 \%)\end{array}$ & $\begin{array}{c}269 \\
(69.9 \%)\end{array}$ & $\begin{array}{c}368 \\
(95.6 \%)\end{array}$ & $\begin{array}{c}342 \\
(88.8 \%)\end{array}$ & $\begin{array}{c}326 \\
(97.0 \%)\end{array}$ & $\begin{array}{c}222 \\
(99.6 \%)\end{array}$ \\
\hline Abnormal & $\begin{array}{c}120 \\
(31.2 \%)\end{array}$ & $\begin{array}{c}116 \\
(30.1 \%)\end{array}$ & $\begin{array}{c}17 \\
(4.5 \%)\end{array}$ & $\begin{array}{c}43 \\
(11.2 \%)\end{array}$ & $\begin{array}{c}10 \\
(3.0 \%)\end{array}$ & $\begin{array}{c}1 \\
(0.4 \%)\end{array}$ \\
\hline \multicolumn{7}{|c|}{ Vaginal discharge smell } \\
\hline Normal & $\begin{array}{c}385 \\
(100 \%)\end{array}$ & $\begin{array}{c}385 \\
(100 \%)\end{array}$ & $\begin{array}{c}384 \\
(99.7 \%)\end{array}$ & $\begin{array}{c}353 \\
(91.7 \%)\end{array}$ & $\begin{array}{c}303 \\
(90.2 \%)\end{array}$ & $\begin{array}{c}221 \\
(99.1 \%)\end{array}$ \\
\hline Abnormal & $\begin{array}{c}0 \\
(0.0 \%)\end{array}$ & $\begin{array}{c}0 \\
(0.0 \%)\end{array}$ & $\begin{array}{c}1 \\
(0.3 \%)\end{array}$ & $\begin{array}{c}32 \\
(8.3 \%)\end{array}$ & $\begin{array}{c}33 \\
(9.8 \%)\end{array}$ & $\begin{array}{c}2 \\
(0.9 \%)\end{array}$ \\
\hline \multicolumn{7}{|c|}{ Color of vaginal discharge } \\
\hline Normal & $\begin{array}{c}385 \\
(100 \%)\end{array}$ & $\begin{array}{c}385 \\
(100 \%)\end{array}$ & $\begin{array}{c}385 \\
(100 \%)\end{array}$ & $\begin{array}{c}385 \\
(100 \%)\end{array}$ & $\begin{array}{c}334 \\
(99.4 \%)\end{array}$ & $\begin{array}{c}218 \\
(97.8 \%)\end{array}$ \\
\hline Abnormal & $\begin{array}{c}0 \\
(0.0 \%)\end{array}$ & $\begin{array}{c}0 \\
(0.0 \%)\end{array}$ & $\begin{array}{c}0 \\
(0.0 \%)\end{array}$ & $\begin{array}{c}0 \\
(0.0 \%)\end{array}$ & $\begin{array}{c}2 \\
(0.6 \%)\end{array}$ & $\begin{array}{c}5 \\
(2.2 \%)\end{array}$ \\
\hline
\end{tabular}


Episiotomy stitches are usually abnormal at 2 hours and 3-6 hours after birth with the rate of $31.2 \%$ and $30.1 \%$, respectively.

Nearly 1 in 10 women have an abnormal vaginal discharge smell from the 3rd day after giving birth (8.3\%). However, by the 5th day, almost all of the women's vaginal discharge was normal $(99.1 \%)$.

The results showed that on the first day and the third day after giving birth, no women had any abnormalities in the color of vaginal discharge. There is a small percentage of women with abnormal vaginal color starting from day 4 postpartum $(0.6 \%)$.

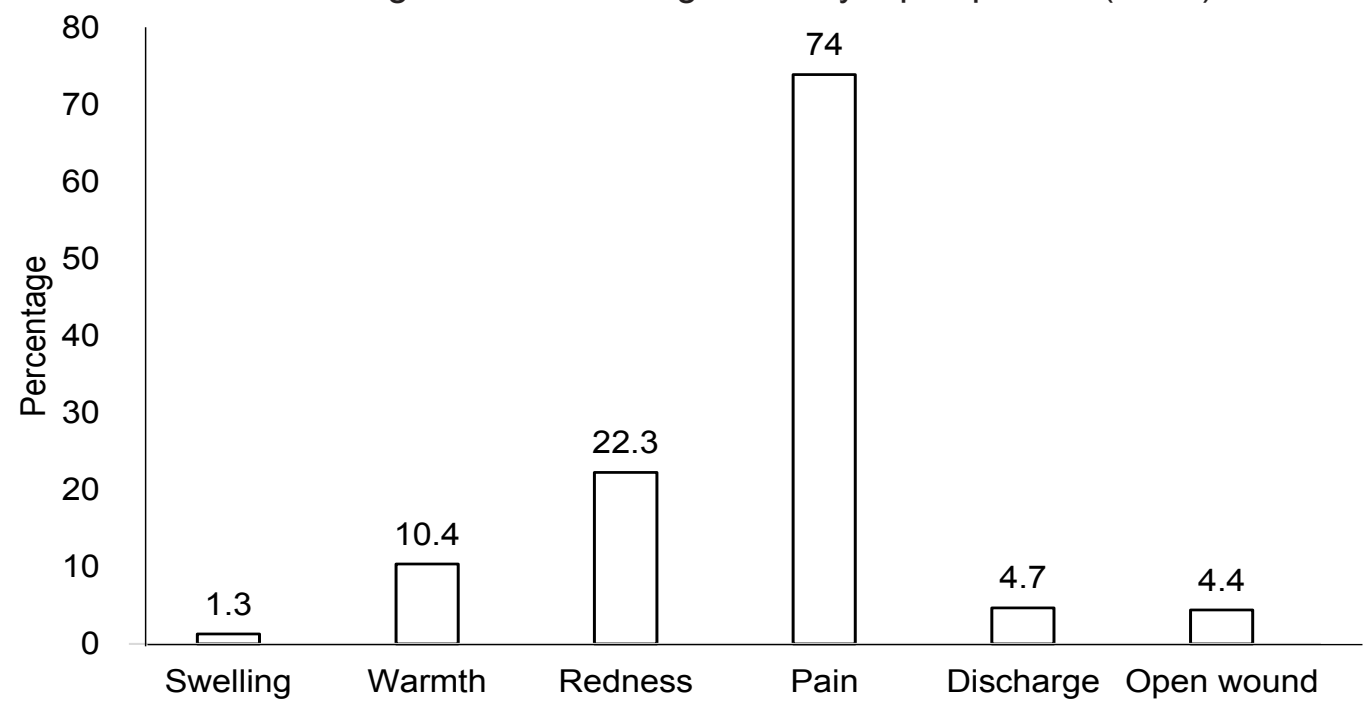

Figure 1. Results of care for episiotomy stitches on the 3rd day after birth The rate of pregnant women having pain is $74 \%$; redness $22.3 \%$; warmth $10.4 \%$.

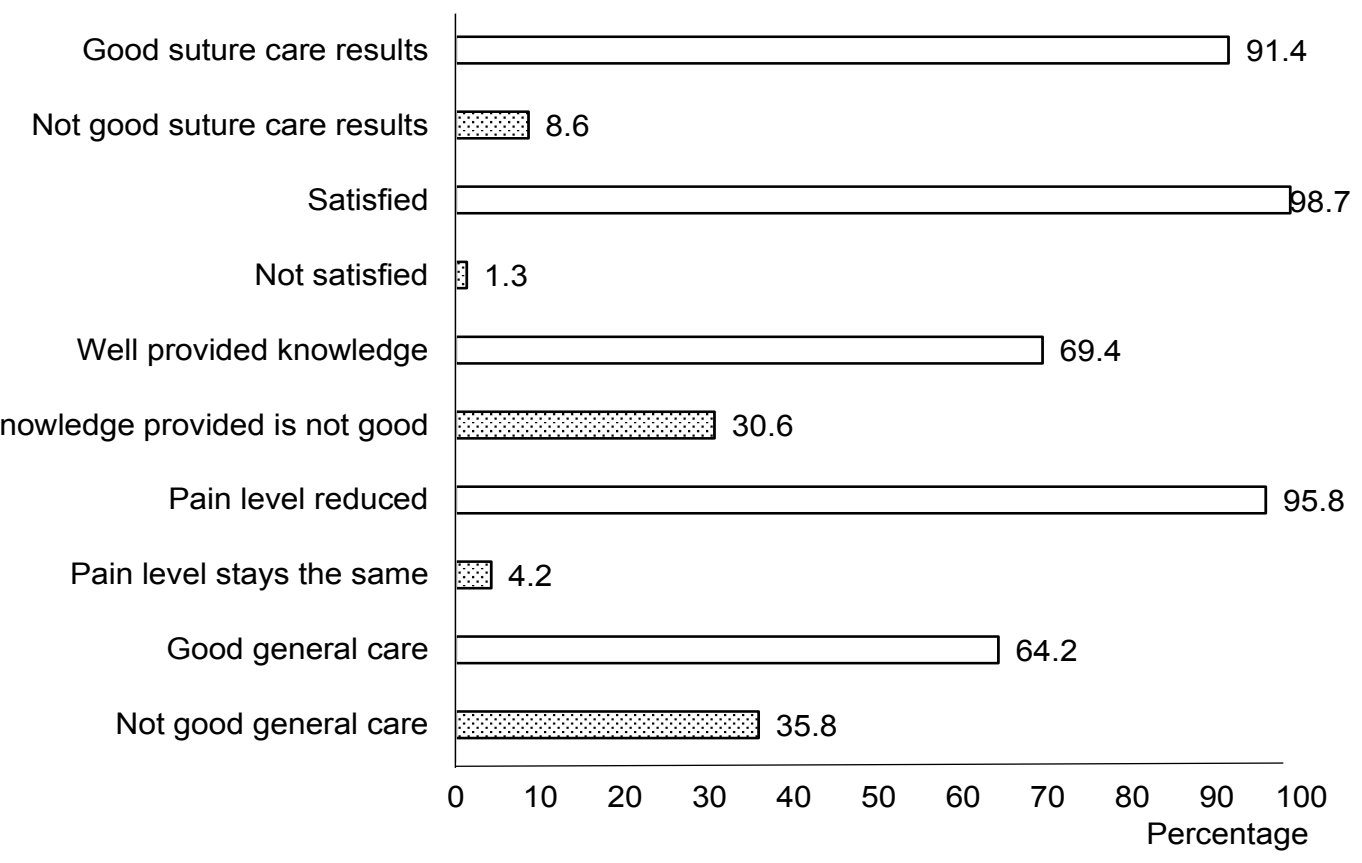

Figure 2. Results of taking care of pregnant women with episiotomy stitches 
$91.4 \%$ of women have good suture care results. $98.7 \%$ of women are satisfied with nursing care. The percentage of women who had good knowledge about the care of the episiotomy stitches was $69.4 \%$. 95.8\% of pregnant women have lower pain level on the 3rd day after giving birth. $64.2 \%$ of pregnant women have good general care results

\section{DISCUSSION}

4.1. Clinical characteristics of postpartum pregnant women with episiotomy stitches

Episiotomy is intended to reduce the incidence of grade III or higher episiotomy tears during first childbirth. In some countries this procedure has become routine. The tear of the perineum is classified into four levels: level I damage to the skin, vaginal mucosa; level II vaginal muscle injury, severe vaginal injury with bilateral vaginal tear; level III extensive tear associated with sheath tear or rupture of the anal sphincter; level IV complex lesions, damage to the anorectal canal mucosa. Our study showed that most of $97.9 \%$ of women have level I episiotomy. These results can be explained because in our study the percentage of pregnant women giving birth for the second time onwards accounted for more than $50 \%$. In women giving birth for the first time, the episiotomy often dilates not as well as women giving birth from the second time onwards, so the rate of women with level I episiotomy tear is quite high. In addition, the extent of damage to the episiotomy mainly depends on the weight of the fetus and the age of the mother.

$97.9 \%$ of pregnant women have episiotomy stitches at level I. Nearly three-quarters of women have episiotomy I stitches at 7 o'clock position (73.2\%). $73.0 \%$ of pregnant women had cut episiotomy, $27.0 \%$ had an episiotomy tear. The rate of women with extra episiotomy tear was $34.0 \%$. $83.4 \%$ of subjects were used nonabsorbable suture. After giving birth, the majority of pregnant women have pain at three level: severe pain, very severe pain, worst possible pain $(75.4 \%)$. There are $26.2 \%$ of women with postpartum complications. Among 101 pregnant women with complications, the rate of each type of postpartum complication was: postpartum urinary retention (48.5\%); postpartum hemorrhage $(23.7 \%)$; perineal vaginal hematoma (10.0\%); infection (3\%) and grade III-IV perineal tear was $1.0 \%$. In general, the percentage of pregnant women with postpartum health problems is quite low, which is also a good sign in postpartum care.

\subsection{Results of postpartum care for pregnant women with episiotomy stitches:}

The results showed that nearly 1 in 10 women have an abnormal vaginal discharge smell from the 3rd day after giving birth $(8.3 \%)$. However, by the 5th day, almost all of the women's vaginal discharge was normal $(99.1 \%)$. The results showed that on the first day and the third day after giving birth, no women had any abnormalities in the color of vaginal discharge. There is a small percentage of women with abnormal vaginal color starting from day 4 postpartum $(0.6 \%)$. Although the abnormality rate is low, it is a dangerous sign that can easily lead to genital infections in the days after the postpartum care period. In the study of Nguyen Kim Anh (2020) in the morning of the 3rd day after giving birth, $83.8 \%$ of 
women had a small amount of discharge and $99.0 \%$ had a dark red discharge [6].

Care for episiotomy stitches is very important to consider and measures should be taken to change dressings, to clean and to designate in case the person is handling suture damage or infection. On the 3rd day after birth, the rate of pregnant women having pain is $74 \%$; redness $22.3 \%$; warmth $10.4 \%$. The result showed that the percentage of women with good suture care results was $91.4 \%$. The finding of Tran Thi Tu Anh study showed $100 \%$ of pregnant women received care [7]. Satisfactory outcomes for women's episiotomy stitches care reflect the effectiveness of maternal care, as a result of prompt and reasonable follow-up and management, leading to quick healing and less scarring. symptoms. The results showed that $98.7 \%$ of women were very satisfied with the nurses in monitoring and taking care of the episiotomy stitches. The finding of Nguyen Thi Tuyet study showed that $93.3 \%$ of pregnant women are satisfied with the care of medical staff at the ward [8]. It means that the percentage of patients who are satisfied with the nursing care is quite high. This result is possible because the nurse is the one who directly asks the patient about the satisfaction level. This may affected the patient's assessment.

Knowledge about postpartum care of mothers plays an important role in helping womenhaveproperandscientificpostpartum care practices, helping to protect and promote women's health in the postpartum period. Knowledge of postpartum care is very basic for pregnant women because it can help early detection and timely treatment of maternal abnormalities. 95.8\% of pregnant women have lower pain level on the 3rd day compared to postpartum.
According to Nguyen Kim Anh (2020) the percentage of pregnant women who feel pain is $98.7 \%$ [6]. Research results showed that in this study $64.2 \%$ of women have good general care outcomes. Nursing care for postpartum women with episiotomy stitches has improved in symptoms in postpartum patients, but more attention should be paid to the nursing process of postpartum care.

The limitation of the study is that our study nurses directly interviewing the patients, so it may affect the patient's subjective assessment of the nursing care.

\section{CONCLUSION}

Most women have good suture care results $(91.4 \%)$. Nearly $100 \%$ of pregnant women are satisfied with nurses in monitoring and caring for episiotomy stitches. The majority of women had good knowledge about episiotomy suture care (69.4\%). $64.2 \%$ of women have good general care outcomes. Nursing care for postpartum pregnant women with episiotomy stitches has reduced patient's symptoms. Should be paid more attention to the nursing process of postpartum care.

\section{REFERENCES}

1. Nguyen Duc Hinh (2002). Preliminary comments on the rate of episiotomy at the Institute for the Protection of Mothers and Newborns in 1999. Research project of the National Hospital of Obstetrics and Gynecology; 482: 64-65.

2. David A Webb, J Culhane (2002). Time of day variation in rates of obstetric intervention to assist in vaginal delivery. Journal of Epidemiology \& Community Health; 56(8): 577-578. http://dx.doi. org/10.1136/jech.56.8.577 
3. Christine L Roberts, Sally Tracy, Brian Peat (2000). Rates for obstetric intervention among private and public patients in Australia: population based descriptive study. BMJ; 321(7254): 137-141. https:// doi.org/10.1136/bmj.321.7254.137

4. Hau Giang general Hospital (2019), Report for the first 6 months of 2019 and plan for the last 6 months of 2019.

5. Ministry of Health (2009), Episiotomy cutting and suturing, National Standard Guidelines for Reproductive Health Services, 80-85.

6. Nguyen Kim Anh (2020), Results of maternal and neonatal health care in the first week after birth in the reproductive health department of Vinh Thuan district health center, Kien Giang province in 2020 , Master's Thesis in Nursing, Thang Long University .

7. Tran Thi Tu Anh, Vu Thi Hoang Lan, Do Manh Hungạnh Hùng (2018). Practice of midwives on maternal and neonatal care after cesarean section at the Obstetrics and Gynecology Department - National Hospital of Obstetrics and Gynecology, 2018. Journal of Pediatrics Research and Practice; 4: 102114. https://doi.org/10.25073/jprp.v0i4.41

8. Nguyen Thi Tuyet and Pham Thi Thuy Thu (2020), Survey on the need for care and satisfaction with the care of pregnant women after vaginal birth at the Department of Reproductive Health Care - Hoai Nhon Town Medical Center, Grassroots level project, Binh Dinh Health Department. 